\title{
Inhaled corticosteroids modulate the (+)insert smooth muscle myosin heavy chain in the equine asthmatic airways
}

\author{
Roxane Boivin, ${ }^{1}$ Amandine Vargas, ${ }^{1}$ Josiane Lefebvre-Lavoie, ${ }^{1}$ Anne-Marie Lauzon, ${ }^{2}$ \\ Jean-Pierre Lavoie ${ }^{1}$
}

- Additional material is published online only. To view please visit the journal online (http://dx.doi.org/10.1136/ thoraxjn-2014-205572)

${ }^{1}$ Department of Clinical Sciences, Faculty of Veterinary Medicine, University of Montreal, St-Hyacinthe, Quebec, Canada ${ }^{2}$ Meakins-Christie Laboratory, Department of Medicine, McGill University, Montreal, Quebec, Canada

Correspondence to Dr Jean-Pierre Lavoie, Department of Clinical Sciences, Faculty of Veterinary Medicine, University of Montreal, 3200 Sicotte, SaintHyacinthe, Quebec, Canada J2S 2M2;

jean-pierre.lavoie@umontreal.

Received 17 April 2014 Revised 8 August 2014 Accepted 15 August 2014

Published Online First

9 September 2014
ABSTRACT

Rationale Overexpression of the (+)insert smooth muscle myosin heavy chain (SMMHC) isoform could contribute to airway bronchospasm by increasing the velocity of contraction. Whether the (+)insert isoform is present in the small airways and its expression is reversible in asthma are unknown.

Objectives To determine the anatomical location and the expression kinetics of the (+)insert SMMHC isoform in airways of horses with heaves and to evaluate its modulation in response to disease status.

Methods We evaluated the (+)insert SMMHC isoform in the airways of horses with heaves during disease exacerbation and remission, and in controls. The expression kinetics of the SMMHC (+)insert was then assessed at multiple time points in two studies: first, in horses with heaves treated for a 1-year period with antigen avoidance alone, inhaled corticosteroids alone or both; second, in horses with heaves before and after a 30-day natural antigen exposure. Gene expression analysis was assessed by quantitative PCR and protein expression was confirmed by targeted mass

spectrometry.

Measurements and main results The $(+)$ insert SMMHC isoform was significantly increased in central and peripheral airways, but not in the trachea of heavesaffected horses in clinical exacerbation when compared horses with heaves in remission and controls. Both corticosteroid administration and antigen avoidance led to a significant reduction of the (+)insert expression in the airways. The (+)insert SMMHC isoform was not significantly increased in airways after 1 month of antigenic re-exposure.

Conclusions The (+)insert SMMHC expression is increased throughout the bronchial tree in horses with heaves and reversible by corticosteroids administration and antigen avoidance.

\section{INTRODUCTION}

Asthma is a chronic lung disease characterised by recurrent episodes of airway inflammation and obstruction. Clinical signs result primarily from bronchospasm but mechanisms leading to airway obstruction remain ill defined. Smooth muscle contraction involves complex interactions between numerous contractile proteins, with actin and myosin playing a central role in this process. Myosin is a homodimer that contains four light chains and two heavy chains. ${ }^{1}$ Alternative splicing of the

\section{Key messages}

\section{What is the key question?}

- Is expression of the (+)insert smooth muscle heavy chain (SMMHC) isoform reversible with antiasthma therapy?

What is the bottom line?

- The (+)insert SMMHC isoform is altered and reversible in equine asthmatic airways and may, therefore, contribute to the modulation of airway mechanics in asthma.

\section{Why read on?}

- This is the first study that demonstrated a reversibility of the expression of the (+)insert isoform either by antigen avoidance strategies or with the administration of inhaled corticosteroids.

myosin gene produces four isoforms of the smooth muscle heavy chain, two of which, the (-)insert and $(+)$ insert, are in the motor domain of the protein. ${ }^{2-4}$ The smooth muscle myosin heavy chain (SMMHC) $(+)$ insert isoform contains a seven-amino acid insert near the ATP binding site that makes ATPase activity approximately twofold greater than that of the $(-)$ insert isoform. $\begin{array}{llll}1 & 3 & 5 & 6 \\ \text { The expression of }(+) \text { insert }\end{array}$ isoform is predominant in phasic smooth muscle such as urinary bladder and small intestine, whereas the (-)insert isoform is mostly expressed in tonic smooth muscle such as aorta, ${ }^{57}$ suggesting that each isoform contributes to the different functional requirements of these muscles. Modulation of the $(+)$ and (-)insert SMMHC isoform was demonstrated during development and pathologies. ${ }^{8} 9$

Recently, it was shown that the (+)insert mRNA was overexpressed in endobronchial biopsies of patients with asthma when compared with controls. ${ }^{10}$ Thus, this isoform could be implicated in airway obstruction by promoting faster contraction of the airway smooth muscle (ASM). Moreover, strains of rats with hyperreactive airways have constitutive increased expression of the (+)insert isoform, ${ }^{10}$ and knockout mice exhibit a slower time course of bronchoconstriction. ${ }^{11}$ Interestingly, in the urinary bladder and intestine, the $(+)$ insert isoform expression decreases with urethral and
To cite: Boivin R, Vargas
Lefebvre-Lavoie J, et al.

Thorax 2014;69:

$1113-1119$. 
intestinal obstruction, ${ }^{9} 12$ and this process is reversible by restoring a normal function of the organs. Ethical considerations prevent longitudinal studies of peripheral lung tissues of human patients, and therefore it is currently unknown whether the (+) insert is overexpressed at different levels in the asthmatic lungs and if its expression is reversible. Heaves is a spontaneously occurring asthma-like disease of horses, characterised by variable and recurring airflow obstruction, airway inflammation and airway remodelling. ${ }^{13-15}$ Thus, we studied heaves-affected horses to first investigate the anatomical location of the $(+)$ insert isoform within the airways and its expression in different states of the disease. We also evaluated the reversibility of its expression by following the same animals over 1-year period, while they were under different antiasthma treatments. Finally, we investigated the re-expression kinetics of this myosin isoform by following a group of horses with heaves reintegrated in a natural antigenic environment, subsequently to a remission period.

\section{METHODS}

\section{Animals}

A total of 26 adult horses (394-580 kg, 12-27 years of age) were studied. Sixteen heaves-affected horses had a history of reversible airway obstruction and inflammation upon hay exposure, whereas control horses $(n=10)$ had no history of respiratory diseases (see table 1). Horses were deemed otherwise

Table 1 Characterisation of the animals, airway function and lung inflammation

\begin{tabular}{|c|c|c|c|c|c|}
\hline Group & $\begin{array}{l}\text { Age } \\
\text { (years) }\end{array}$ & $\begin{array}{l}\text { Weight } \\
\text { (kg) }\end{array}$ & Sex & $\begin{array}{l}\text { Airway } \\
\text { resistance } \\
\text { after antigen } \\
\text { challenge (cm } \\
\left.\mathrm{H}_{2} \mathrm{O} / \mathrm{L} / \mathrm{s}\right)\end{array}$ & $\begin{array}{l}\text { Neutrophils } \\
\text { count in BALF } \\
\text { after antigen } \\
\text { challenge (\%) }\end{array}$ \\
\hline Control & 15 & 497 & Mare & 0.52 & 18 \\
\hline Control & 16 & 475 & Mare & 0.81 & 1 \\
\hline Control & 18 & 394 & Gelding & 0.87 & 2 \\
\hline Control & 18 & 425 & Mare & 0.38 & 4 \\
\hline Control & 19 & 494 & Gelding & 0.43 & 2 \\
\hline Control & 22 & 444 & Mare & 0.44 & 1 \\
\hline Control & 23 & 490 & Mare & 0.47 & 24 \\
\hline Control & 27 & 508 & Mare & 1.02 & 8 \\
\hline Control & 16 & 453 & Mare & 0.53 & 18 \\
\hline Control & 12 & NA & Mare & 0.30 & 2 \\
\hline Heaves & 18 & 443 & Mare & 2.63 & 37 \\
\hline Heaves & 20 & 452 & Mare & 2.87 & 42 \\
\hline Heaves & 20 & 506 & Gelding & 2.37 & 64 \\
\hline Heaves & 23 & 442 & Gelding & 2.02 & 37 \\
\hline Heaves & 21 & 477 & Gelding & 1.83 & 38 \\
\hline Heaves & 26 & 480 & Mare & 3.44 & 32 \\
\hline Heaves & 22 & 440 & Mare & 2.12 & 42 \\
\hline Heaves & 14 & 580 & Mare & 3.83 & 25 \\
\hline Heaves & 17 & 546 & Mare & 2.49 & 36 \\
\hline Heaves & 20 & 570 & Gelding & 2.10 & 63 \\
\hline Heaves & 17 & 555 & Gelding & 3.07 & 25 \\
\hline Heaves & 23 & 475 & Mare & 4.37 & 48 \\
\hline Heaves & 19 & 472 & Mare & 1.70 & 35 \\
\hline Heaves & 19 & 491 & Mare & 2.39 & NA \\
\hline Heaves & 16 & 462 & Mare & 3.27 & 20 \\
\hline Heaves & 20 & 444 & Gelding & 2.15 & 42 \\
\hline
\end{tabular}

BALF, bronchoalveolar lavage fluid; NA, not appropriate. healthy. All experimental procedures were performed in accordance with the Canadian Council for Animal Care guidelines.

\section{Pulmonary function and bronchoalveolar lavage fluid cytology}

Lung function was measured in unsedated standing horses, using a pneumotachograph attached to a mask and an oesophageal balloon catheter as previously described. ${ }^{16}$ Bronchoalveolar lavages (BAL) were performed using $2 \times 250 \mathrm{~mL}$ boluses of isotonic saline instilled in the main bronchi through a $2.5 \mathrm{~m}$ videoendoscope (Olympus Medical System Corp, Tokyo, Japan). ${ }^{17}$ Thin-layer cell from BAL fluid was prepared with a cytocentrifuge (Cytospin2, Shandon, Fisher Scientific, Waltham, Massachusetts, USA) and stained with a modified WrightGiemsa solution (DiffQuick, Fisher Scientific, Waltham, Massachusetts, USA). Differential cell counts were obtained from 400 cells.

\section{Design}

Study 1

Eight controls and six heaves-affected horses were antigen exposed by being stabled and fed hay for $\geq 3$ weeks. Three additional horses with heaves were pastured for $\geq 3$ months to induce clinical remission. Animals were euthanised and the lungs and trachea were removed.

\section{Study 2}

Horses were part of a larger study evaluating the effects of inhaled corticosteroids on airway remodelling, and the animals, experimental protocol, physiological, inflammatory and selected remodelling features have been reported previously. ${ }^{18}$ In brief, 11 adult heaves-affected horses were housed indoors and exposed to hay until they all exhibited clinical signs suggesting airflow obstruction (Baseline). Antigen exposition induced an airflow limitation in horses with heaves with increased pulmonary resistance and lung elastance values. The antigen avoidance group consisted of five horses at pasture without hay feeding as sole therapy. The remaining six horses were treated with inhaled fluticasone propionate (Flovent HFA, GlaxoSmithKline, Montreal, Quebec, Canada) while being stabled and exposed to hay for the first 6 months and then turned out on pasture for 6 months with continued treatment with fluticasone. Pulmonary function, BAL fluid and endobronchial biopsies (see below) were obtained at baseline and then $1,3,6,7$ and 12 months later. As previously reported, ${ }^{18}$ both treatments resulted in improved airway function, although it was more rapidly observed when horses were treated with inhaled fluticasone than with antigen avoidance strategies alone. Conversely, normalisation of BALF neutrophilia was present only when horses were at pasture without hay feeding.

\section{Study 3}

These horses were part of a larger study evaluating the asthmatic remodelling and inflammation. ${ }^{19}$ In a prospective study, six horses with heaves and five age-matched controls were kept in an antigen poor environment (pasture) $\geq 3$ months prior to study. Both groups were then stabled and fed hay for a month. Horses with heaves, but not controls, developed airway neutrophilia and obstruction with stabling and hay feeding. Endobronchial biopsies were collected prior to antigen exposure and then $24 \mathrm{~h}$ and 30 days following exposure. 


\section{Airways, smooth muscle and endobronchial biopsies}

Smooth muscle from main bronchi and trachea were dissected on ice and stored at $-80^{\circ} \mathrm{C}$. Airways were also dissected from the parenchyma, placed in liquid nitrogen, then classified as peripheral ( $\leq 10 \mathrm{~mm}$ of diameter) or intermediate $(10-25 \mathrm{~mm}$ of diameter) airways and stored at $-80^{\circ} \mathrm{C}$. Endobronchial biopsies were obtained using disposable forceps (standard fenestrated and smooth, $2.3 \mathrm{~m}$, Olympus Medical Systems Corp, Tokyo, Japan) from different branching sites, starting approximately $30 \mathrm{~cm}$ distal to the carina and moving cranially. ${ }^{19}$ Biopsies were placed in RNAlater for $24 \mathrm{~h}$ at $4^{\circ} \mathrm{C}$ then stored at $-80^{\circ} \mathrm{C}$.

\section{RNA extraction}

Total RNA extraction was performed on airways and smooth muscle using TRIzol Reagent (Invitrogen, Brulington, ON, CA) for study 1 , and on two endobronchial biopsies per horse, for studies 2 and 3, using RNeasy Plus Mini Kit (Qiagen, Burlington, ON, CA). RNA concentration and purity were evaluated by spectrophotometry.

\section{Reverse transcription}

Reverse transcription of mRNA was performed using Superscript III $200 \mathrm{U} / \mu \mathrm{L}$ (Invitrogen, Burlington, ON, CA) in the presence of RNasin Ribonuclease inhibitor $10000 \mathrm{U}$ (Promega, Madison, Wisconsin, USA) and Oligo(dt) primers $0.5 \mu \mathrm{g} / \mu \mathrm{L}$ (Invitrogen, Burlington, ON, CA). Details are provided in the online supplement. Samples were reverse transcribed and purified in duplicate, that is, two repeats of the same mRNA sample.

\section{Quantitative PCR}

Real-time PCR was performed using the Rotor-Gene RG3000 (Corbett Research, Sydney, AS) with the QuantiTect SYBR Green PCR Kit (Qiagen, Toronto, Ontario, Canada) according to the manufacturer's instructions, with minor modifications. Details are provided in the online supplement. Primers were designed to span exon-intron boundaries to prevent amplification of genomic DNA (table 2). Samples were run in duplicate with an appropriate negative control.

\section{$(+)$ Insert relative protein analysis}

Proteins were extracted from bronchial smooth muscle using Tissue Protein Extraction Reagent from Fisher Scientific (Waltham, Massachusetts, USA) and quantified by a standard Bradford assay. Thirty micrograms of each sample was loaded on $10 \%$ sodium dodecyl sulfate polyacrylamide gel (BioRad, Hercules, California, USA). Bands of interest $(228 \mathrm{kDa})$ were cut and sent to the Quebec Genomics Center (Quebec, Canada) for relative quantification of (+)insert isoform by targeted mass spectrometry (see online supplementary for detailed method).

Table 2 Sequences of primer pairs used for quantitative PCR analysis

\begin{tabular}{ll}
\hline 5'-ATTCTATGCACAGGCGAGTCTGGA-3' $^{\prime}$ & SMMHC (+)insert forward \\
5'-GTAGGCAAGAGGTGGGCCTTG-3' $^{\prime}$ & SMMHC (+)insert reverse \\
5'-TGAACAAGGCCCTGGACAAGAC-3' $^{\prime}$ & Total SMMHC forward \\
5'-TGCAGCTTCTCGTTGGTGTAGT-3' $^{\prime}$ & Total SMMHC reverse \\
\hline
\end{tabular}

SMMHC, smooth muscle myosin heavy chain.

\section{Statistical analysis}

For study 1, group characteristics were analysed by a MannWhitney $U$ test and physiological and protein data by a one-way analysis of variance (ANOVA) with Turkey's post-hoc test. Within-group and between-group differences were evaluated using a priori contrasts. For studies 2 and 3, data were evaluated by repeated-measure ANOVA and a priori contrasts. The software SAS V.9.2 was used and $\mathrm{p}<0.05$ was considered significant.

\section{RESULTS}

Study 1

Age, weight and sex were not statistically different between groups (control (mean \pm SD): 19.8 \pm 1.4 years, heaves: 21.3 \pm 1.1 years, remission: $20.3 \pm 1.3$ years; $466 \pm 14 \mathrm{~kg}, 467 \pm 10 \mathrm{~kg}$ and $501 \pm 27 \mathrm{~kg}$; and $2 / 8,3 / 6$ and $1 / 3$ mares and the remaining animals were castrated males). Horses with heaves under antigen exposure (stabling and hay feeding) developed airway obstruction, whereas heaves-affected horses in a low antigen environment (figure 1A, B) and control horses had normal lung function. Similarly, the percentage of neutrophils in BAL fluid was significantly increased with antigen exposure in horses with heaves when compared with controls $(\mathrm{p}<0.0001)$ and to horses in clinical remission $(\mathrm{p}=0.0002$; figure $1 \mathrm{C})$.

The (+)insert SMMHC isoform expression to total myosin ratios were twofold to threefold increased in bronchial smooth muscle of horses with heaves in exacerbation when compared with controls whether mRNA (figure 2A) or protein (figure 2B) levels were evaluated. Furthermore, the $(+)$ insert SMMHC isoform mRNA expression to total myosin ratio was significantly increased in bronchial smooth muscle, intermediate and peripheral airways of horses with heaves in crisis compared with controls $(p<0.0001, p=0.0005$ and $p=0.004$, respectively) and to horses with heaves in remission $(p<0.0001, p<0.0001$ and $p=0.002$, respectively). However, there was no significant difference in $(+)$ insert isoform expression to total myosin ratio between groups in tracheal smooth muscle. The $(+)$ insert isoform protein normalised to total myosin was similarly significantly increased in the bronchi of heaves-affected horses when compared with controls $(p=0.002)$, but not during clinical remission of the disease $(p=0.083)$. There was no significant difference in protein expression between control horses and heaves-affected horses during disease remission $(p=0.500)$.

\section{Study 2: reversibility of (+)insert expression with the remission of the disease}

To confirm the reversibility of the (+)insert isoform expression in a given animal, we studied endobronchial biopsies of heaves-affected horses before and after treatments with fluticasone or antigen avoidance (study 2). Both treatments resulted in a twofold reduction on average of (+)insert isoform (figure 3; $\mathrm{p}=0.003$ and $\mathrm{p}=0.020$ ) after 3 months, and levels were maintained up to month 12 . Healthy control horses were not evaluated in this experiment.

\section{Study 3: (+)insert does not increase within a month of antigen exposure}

No significant differences in (+)insert isoform expression were observed in horses with heaves or in controls throughout the 30-day continuous antigenic re-exposure study $(\mathrm{p}=0.433)$. However, large variability was seen between horses after 30 days where two of the six horses with heaves exhibited a 

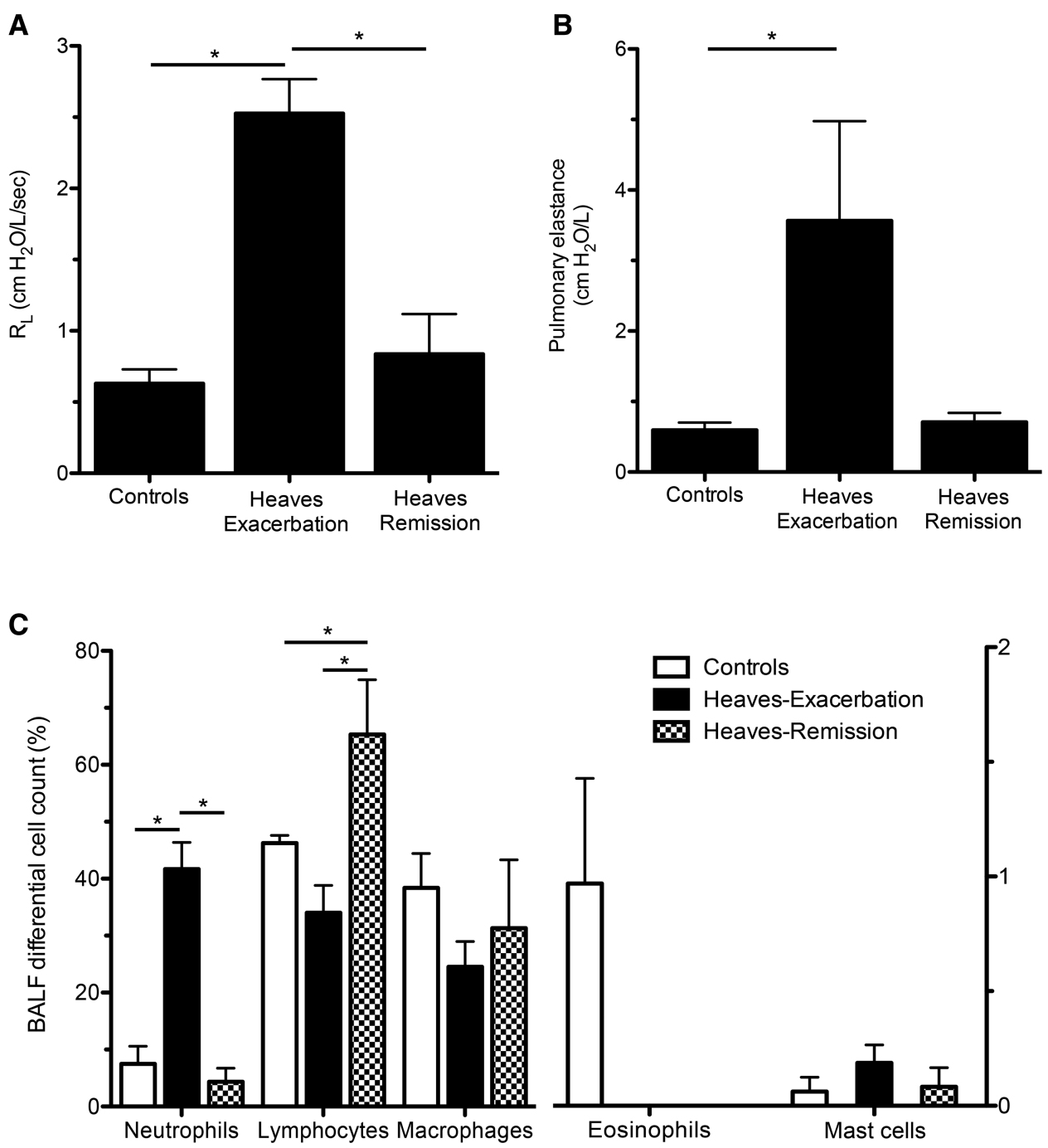

Figure 1 Pulmonary function and bronchoalveolar lavage fluid. (A) Pulmonary resistance, (B) elastance and (C) bronchoalveolar lavage fluid (BALF) differential cell count of control horses $(n=8)$, heaves-affected horses in clinical exacerbation $(n=6)$ and in clinical remission $(n=3)$ for study 1 . Mean \pm SEM. *Different between groups. $p<0.05$.

twofold to threefold increase in (+)insert isoform expression (study 3; figure 4).

\section{DISCUSSION}

Bronchoconstriction is a hallmark of human asthma, but its underlying mechanisms remain elusive. Factors possibly contributing to the increased ASM mass observed in asthmatic airways have generated considerable interest because of the potential to lead to increased force generation. ${ }^{20}$ Studies have also suggested a greater shortening velocity of asthmatic ASM, ${ }^{21}$ but this has not been observed at the single muscle strip level. ${ }^{22}$ These experiments are, however, difficult to perform in human subjects because of the effects of medications, which may influence the contractile protein make-up of the ASM. Nonetheless, a recent study reported an altered ASM composition, with increased mRNA expression of the fast $(+)$ insert isoform in the central airways of asthmatic subjects. ${ }^{10}$ The increased rate of contraction provided by the $(+)$ insert isoform in phasic tissues ${ }^{23}$ suggests that this isoform could potentially accentuate bronchoconstriction by counteracting the dilating effects of tidal breathing. The present study demonstrates that the $(+)$ insert isoform is overexpressed in both large and small airways in an equine model of asthma. Furthermore, this overexpression is reversible with both inhaled corticosteroids and antigen avoidance strategies. Taken together, these results indicate a potential role for the $(+)$ insert isoform in airway hyperresponsiveness and asthma. The expression of this isoform was not modulated by disease status in tracheal smooth muscle, suggesting that the intrapulmonary environment contributes to the changes in $(+)$ insert isoform expression.

We chose to study equine heaves as, unlike other animal models and in humans, this condition allows the prospective study of the central and peripheral airways of the same subject, and in asymptomatic and symptomatic stages of the disease. Neutrophils are predominant cells present in the airway lumen in heaves. Interestingly, while airway eosinophilia is uncommon in heaves, it is now recognised that neutrophils are also present in the airway secretions of a significant proportion of asthmatics, ranging from mild to severe. ${ }^{24-30}$ Also, clinical improvement is observed in these horses with common asthma medication such as corticosteroids and bronchodilators and also through antigen avoidance strategies, which is difficult to implement in humans. In contrary to smaller animal models, the size of the airways in horses also allows for macroscopic dissection of ASM.

Previous studies have demonstrated that the presence of the (+)insert SMMHC isoform doubles the propulsion velocity of 
A

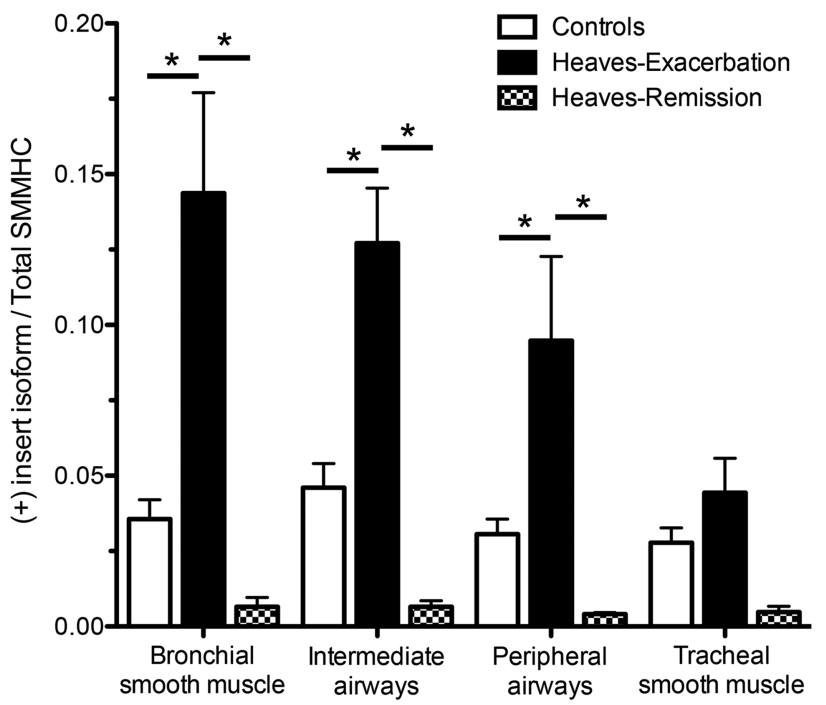

B

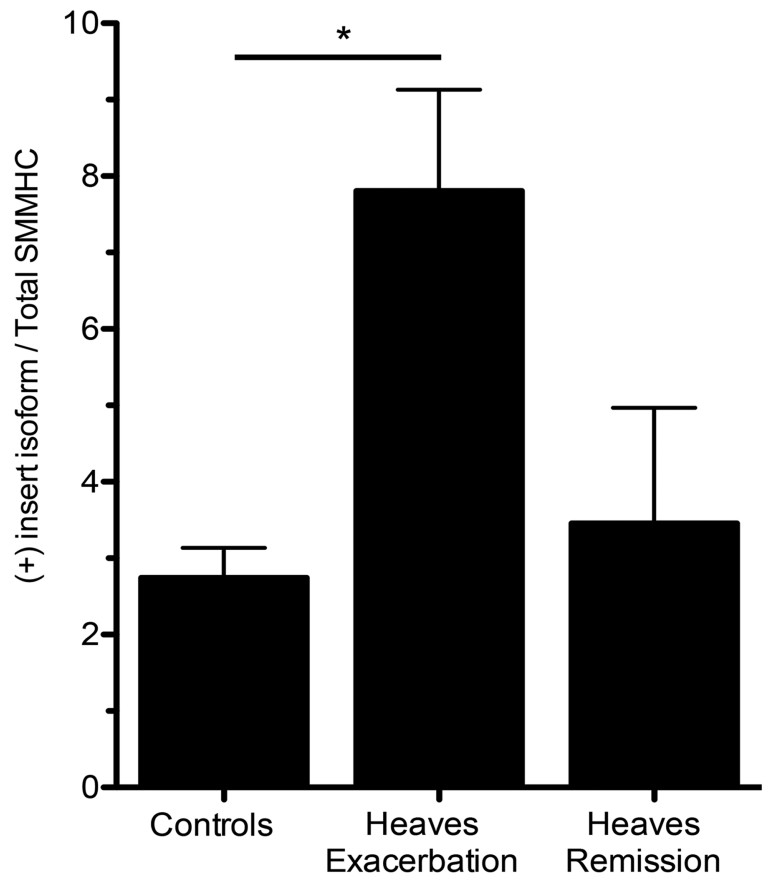

Figure 2 Relative quantification of (+)insert isoform in bronchial tree of horses. (A) Total RNA was extracted from airways of control horses (white bars; $n=8$ ), heaves-affected horses in clinical exacerbation (black bars; $\mathrm{n}=6$ ) and heaves-affected horses in clinical remission (chess bars; $\mathrm{n}=3$ ). Expression of $(+)$ insert was measured by quantitative $\mathrm{PCR}$ and reported to total SMMHC expression. Mean \pm SEM of quantified levels from experiments performed in duplicate, that is, two repeats on the same RNA sample; (B) proteins were extracted from bronchial smooth muscle of control horses $(n=8)$, heaves-affected horses in clinical exacerbation $(n=6)$ and heaves-affected horses in clinical remission $(n=3)$. Expression of $(+)$ insert was measured by targeted mass spectrometry and reported on expression of total SMMHC. Mean \pm SEM of quantified levels from experiments performed in duplicate, that is, two repeats on the same protein sample. *Different between groups. $\mathrm{p}<0.05$.

actin filament in an in vitro motility assay. ${ }^{51}$ Thus, it has been suggested that a differential expression of this isoform could contribute to altering the contractile properties of ASM in

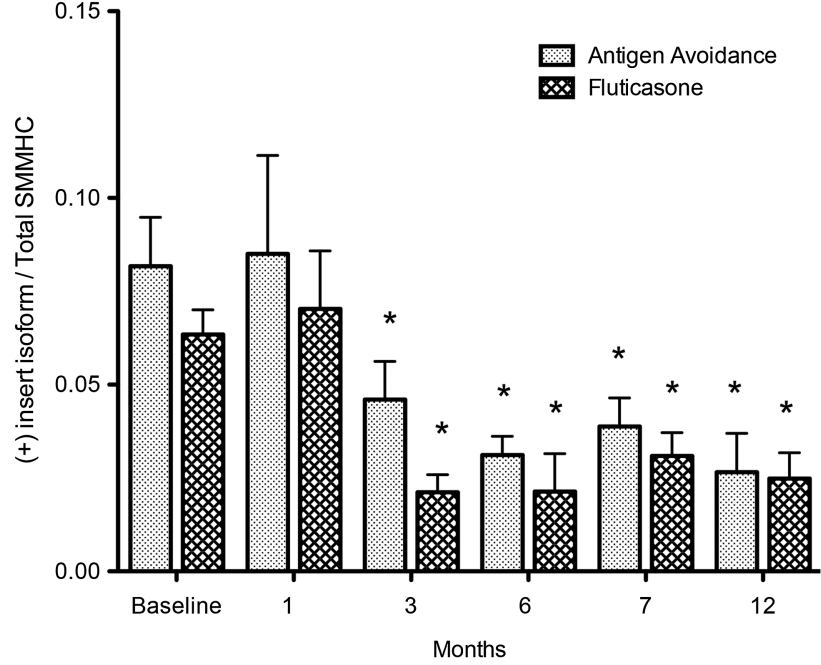

Figure 3 Reversibility of (+)insert isoform expression. Total RNA was extracted from two endobronchial biopsies of heaves-affected horses either treated with antigen avoidance (light grey bars; $n=5$ ) or inhaled corticosteroids (dark grey bars; $n=6)$. Expression of (+)insert isoform and total SMMHC was analysed by real-time PCR with appropriate negative control. Expression of (+)insert was reported to total SMMHC expression. Mean $\pm S E M$ of quantified levels from experiments performed in duplicate, that is, two repeats on the same RNA sample. ${ }^{*}$ Different from baseline (month 0 ) in the same group. $p<0.05$.

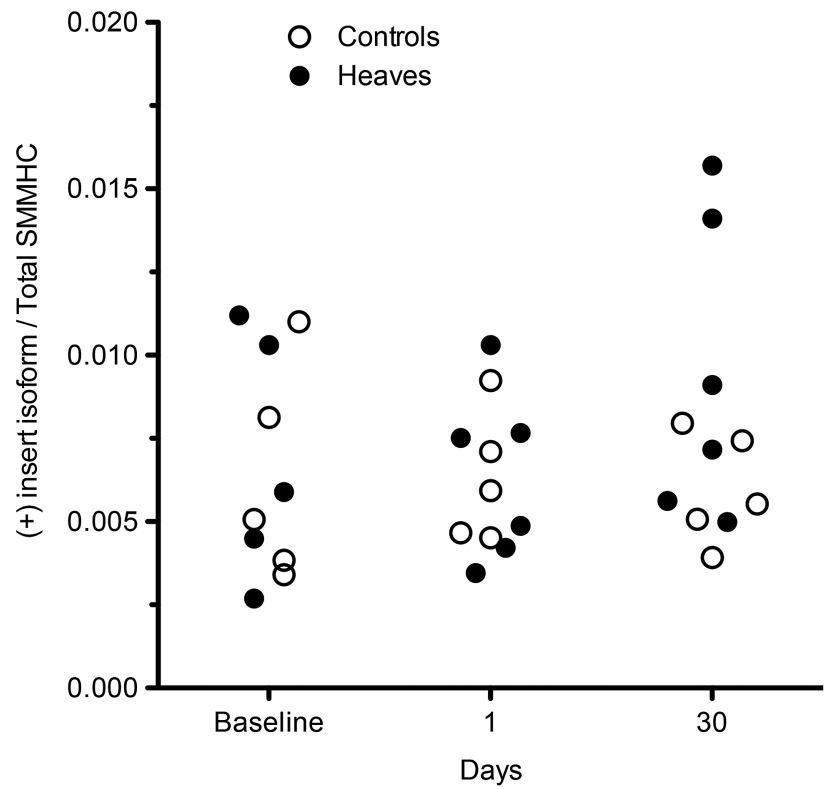

Figure 4 Kinetics of (+)insert SMMHC isoform expression. Total RNA was extracted from two endobronchial biopsies of controls (open circles; $n=5$ ) and heaves-affected horses (black circles; $n=6$ ). Expression of (+)insert isoform and total SMMHC was analysed by real-time PCR with appropriate negative control. Expression of (+)insert was reported to total SMMHC expression. Mean \pm SEM of quantified levels from experiments performed in duplicate, that is, two repeats on the same RNA sample.

asthma. ${ }^{2}$ In the current study, we observe for the first time that the $(+)$ insert isoform is present in the entire bronchial tree, and that its expression varies according to disease status. These findings correlate with the distribution pattern of the smooth muscle thickening (remodelling) observed in the airways of 
heaves-affected horses, ${ }^{15} 32$ which was also found in human subjects with type II asthma. ${ }^{33}$ However, the tracheal smooth muscle did not show a differential expression of this myosin isoform with disease state, which suggests that this tissue may not be implicated in the disease. It is conceivable that inflammatory mediators do not affect the extrapulmonary trachealis muscle as much as the intrapulmonary ASM. Alternatively, the presence of almost complete cartilage rings may reduce tidal breathing-induced length changes in the trachealis muscle. The difference in dynamic environment may affect the type of remodelling that occurs in the muscle and these findings also suggest that results obtained using trachea may not be representative of bronchial smooth muscle behaviour.

The increased (+)insert isoform to total SMMHC ratio during clinical exacerbation is not permanent, as it can be reversed by antigenic avoidance strategies (studies 1 and 3 ) or by the use of inhaled corticosteroids despite continuous antigen challenge and persisting airway inflammation (study $2^{18}$ ). In study 2, the decrease of the (+)insert isoform to total SMMHC ratio coincided with the normalisation of pulmonary neutrophilia only in the antigen avoidance-treated group. However, in contrast with the (+)insert isoform to total SMMHC ratio, pulmonary neutrophilia was not significantly altered by corticosteroid treatment in the absence of antigen avoidance strategies. Moreover, we also showed a dissociation of (+)insert isoform to total SMMHC ratio from airway neutrophilia following a 30-day of antigen exposure and bronchoconstriction (study 3). From these results, one could conclude that inflammation is not required for the modulation of the (+)insert isoform isoform expression. However, the timeline of events may be more complex.

As lung function improvement precedes normalisation of the $(+)$ insert isoform expression at least in the fluticasone group, the (+)insert isoform expression cannot be solely responsible for the lung function changes observed.

These results suggest that of the multiple changes occurring in ASM and other airway wall components, some factors contributing to altered lung function act prior to the changes in the $(+)$ insert isoform to total SMMHC ratio. The (+)insert changes may still contribute to the change in pulmonary resistance by making it more stiff. One possible mechanism by which this may occur is by changes in the dynamic environment of the ASM as the lung function changes. As the lung elastance decreases rapidly upon antigen avoidance and corticosteroid treatment, ${ }^{18}$ the ASM will experience increased length oscillations from tidal breathing. It has previously been shown in in vitro studies that ASM cells respond to oscillatory forces with reorganisation of its contractile protein network. ${ }^{34}$ Furthermore, findings obtained in the intestine and the urinary bladder showed that mechanical obstruction can modulate the $(+)$ insert isoform expression. ${ }^{9} 12$

The (+)insert isoform is only one of the potential contractile proteins that can be altered in smooth muscle to lead to its phenotype changes. It is, therefore, not surprising that its time course of alterations is not perfectly matched with the inflammatory cells and pulmonary mechanical parameters measured here. The improvement in airway resistance and elastance in these horses ${ }^{18}$ preceded the decrease of the $(+)$ insert isoform expression in study 2 , and we did not observe a significant correlation between the (+)insert isoform and these measures (data not shown). Furthermore, in study 3, severe airway obstruction was present in all heaves-affected horses after 30 days of antigen challenge, ${ }^{19}$ while only two of the six horses had increased expression of $(+)$ insert isoform. Thus, $(+)$ insert isoform would not be directly implicated in the initial clinical symptoms. Other studies have also failed to correlate the (+)insert isoform expression with smooth muscle mechanical properties. ${ }^{35-37}$ Thus, this suggests that the expression of a number of contractile proteins, such as myosin light chain kinase and actin regulatory proteins, may also need to be altered in concert with the (+)insert isoform to alter the smooth muscle mechanics. Similarly, neutrophils may not have any role to play in directly altering the contractile protein expression, but potentially other inflammatory cells or cytokines may be responsible for orchestrating the changes in smooth muscle contractile properties.

\section{CONCLUSION}

In summary, we showed that the (+)insert SMMHC isoform expression was increased in bronchial smooth muscle at the both mRNA and protein levels of heaves-affected horses and that its expression was reversible either by antigen avoidance or by administration of inhaled corticosteroids. Thus, our results demonstrate that ASM phenotype is altered throughout the bronchial tree, but not in trachealis muscle, in this naturally occurring asthmatic disease of horses. The sequence of events required to lead to such alterations in ASM and the key players required to lead to such changes will require further investigations. Furthermore, the modulation of the $(+)$ insert isoform by corticosteroids in the present study should be taken into account when studying human asthmatic ASM phenotype. These conclusions should, nevertheless, be ascertained in larger equine and human cohorts, and the sequence of events leading to alterations in the (+)insert SMMHC isoform and the key players involved for these changes require further investigations.

Acknowledgements The authors thank Dr Mathilde Leclere for providing data, Isabelle Kelly for mass spectrometry experiment, Guy Beauchamp for statistical analysis and Gijs IJpma for his help with the manuscript.

Contributors $R B, J L-L$ and J-PL involved in conception and study design; $R B, A V$, $J L-L, A-M L$ and J-PL in analysis and interpretation and RB, AV, AML and J-PL in drafting the manuscript for important intellectual content.

Funding This work was supported by the Canadian Institutes of Health Research (CIHR) grant number is \#102751.

Competing interests None.

Provenance and peer review Not commissioned; externally peer reviewed.

\section{REFERENCES}

1 White $S$, Martin AF, Periasamy M. Identification of a novel smooth muscle myosin heavy chain CDNA: isoform diversity in the $S 1$ head region. Am J Physiol 1993;264: C1252-8.

2 Lauzon AM, Trybus KM, Warshaw DM. Molecular mechanics of two smooth muscle heavy meromyosin constructs that differ by an insert in the motor domain. Acta Physiol Scand 1998;164:357-61.

3 Leguillette R, Gil FR, Zitouni N, et al. (+)Insert smooth muscle myosin heavy chain (SM-B) isoform expression in human tissues. Am J Physiol Cell Physiol 2005;289: C1277-85.

4 Low R, Leguillette R, Lauzon AM. (+)Insert smooth muscle myosin heavy chain (SM-B): from single molecule to human. Int J Biochem Cell Biol 2006;38:1862-74.

5 Lauzon AM, Tyska MJ, Rovner AS, et al. A 7-amino-acid insert in the heavy chain nucleotide binding loop alters the kinetics of smooth muscle myosin in the laser trap. J Muscle Res Cell Motil 1998;19:825-37.

6 Kelley CA, Takahashi M, Yu JH, et al. An insert of seven amino acids confers functional differences between smooth muscle myosins from the intestines and vasculature. J Biol Chem 1993;268:12848-54.

7 Gil FR, Lauzon AM. Smooth muscle molecular mechanics in airway hyperresponsiveness and asthma. Can J Physiol Pharmacol 2007;85:133-40.

8 Babij P. Tissue-specific and developmentally regulated alternative splicing of a visceral isoform of smooth muscle myosin heavy chain. Nucleic Acids Res 1993;21:1467-71.

9 DiSanto ME, Stein R, Chang $S$, et al. Alteration in expression of myosin isoforms in detrusor smooth muscle following bladder outlet obstruction. Am J Physiol Cell Physiol 2003;285:C1397-410. 
10 Leguillette R, Laviolette M, Bergeron C, et al. Myosin, transgelin, and myosin light chain kinase: expression and function in asthma. Am J Respir Crit Care Med 2009;179:194-204.

11 Tuck SA, Maghni K, Poirier A, et al. Time course of airway mechanics of the (+) insert myosin isoform knockout mouse. Am J Respir Cell Mol Biol 2004;30:326-32.

12 Lofgren M, Fagher K, Wede OK, et al. Decreased shortening velocity and altered myosin isoforms in guinea-pig hypertrophic intestinal smooth muscle. J Physiol 2002:544:707-14.

13 Lowell F. Observations on heaves: an asthma-like syndrome in the horse. J Allergy 1964:35:322-30

14 Hirst SJ, Martin JG, Bonacci JV, et al. Proliferative aspects of airway smooth muscle. J Allergy Clin Immunol 2004;114:S2-S17.

15 Herszberg B, Ramos-Barbon D, Tamaoka M, et al. Heaves, an asthma-like equine disease, involves airway smooth muscle remodeling. J Allergy Clin Immunol 2006;118:382-8.

16 Jean D, Vrins A, Lavoie JP. Monthly, daily, and circadian variations of measurements of pulmonary mechanics in horses with chronic obstructive pulmonary disease. Am J Vet Res 1999;60:1341-6.

17 Lavoie JP, Maghni K, Desnoyers M, et al. Neutrophilic airway inflammation in horses with heaves is characterized by a Th2-type cytokine profile. Am J Respir Crit Care Med 2001;164:1410-3

18 Leclere $\mathrm{M}$, Lavoie-Lamoureux $\mathrm{A}$, Joubert $\mathrm{P}$, et al. Corticosteroids and antigen avoidance decrease airway smooth muscle mass in an equine asthma model. Am J Respir Cell Mol Biol 2012;47:589-96.

19 Leclere M, Lavoie-Lamoureux A, Gelinas-Lymburner $\mathrm{E}$, et al. Effect of antigenic exposure on airway smooth muscle remodeling in an equine model of chronic asthma. Am J Respir Cell Mol Biol 2011;45:181-7.

20 Kudo M, Ishigatsubo Y, Aoki I. Pathology of asthma. Front Microbiol 2013;4:263.

21 Brown RH, Scichilone N, Mudge B, et al. High-resolution computed tomographic evaluation of airway distensibility and the effects of lung inflation on airway caliber in healthy subjects and individuals with asthma. Am J Respir Crit Care Med 2001;163:994-1001

22 Chin LY, Bosse Y, Pascoe C, et al. Mechanical properties of asthmatic airway smooth muscle. Eur Respir J 2012;40:45-54.

23 Huang Q, Babu GJ, Periasamy M, et al. SMB myosin heavy chain knockout enhances tonic contraction and reduces the rate of force generation in ileum and stomach antrum. Am J Physiol Cell Physiol 2013;304:C194-206.
24 Asman B, Strand V, Bylin G, et al. Peripheral neutrophils after allergic asthmatic reactions. Int J Clin Lab Res 1997:27:185-8.

25 Fahy JV, Kim KW, Liu J, et al. Prominent neutrophilic inflammation in sputum from subjects with asthma exacerbation. J Allergy Clin Immunol 1995:95:843-52.

26 Lamblin C, Gosset P, Tillie-Leblond I, et al. Bronchial neutrophilia in patients with noninfectious status asthmaticus. Am J Respir Crit Care Med 1998; 157:394-402

27 Louis R, Lau LC, Bron AO, et al. The relationship between airways inflammation and asthma severity. Am J Respir Crit Care Med 2000;161:9-16.

28 Norzila MZ, Fakes K, Henry RL, et al. Interleukin-8 secretion and neutrophil recruitment accompanies induced sputum eosinophil activation in children with acute asthma. Am J Respir Crit Care Med 2000;161:769-74.

29 Sur S, Crotty TB, Kephart GM, et al. Sudden-onset fatal asthma. A distinct entity with few eosinophils and relatively more neutrophils in the airway submucosa? Am Rev Respir Dis 1993;148:713-9.

30 Turner M0, Hussack $P$, Sears MR, et al. Exacerbations of asthma without sputum eosinophilia. Thorax 1995;50:1057-61.

31 Leguillette R, Zitouni NB, Govindaraju K, et al. Affinity for MgADP and force of unbinding from actin of myosin purified from tonic and phasic smooth muscle. Am J Physiol Cell Physiol 2008;295:C653-60.

32 Leclere M, Lavoie-Lamoureux A, Lavoie JP. Heaves, an asthma-like disease of horses. Respirology 2011;16:1027-46

33 Ebina $M$, Yaegashi $H$, Chiba $R$, et al. Hyperreactive site in the airway tree of asthmatic patients revealed by thickening of bronchial muscles. A morphometric study. Am Rev Respir Dis 1990;141:1327-32.

34 Nagayama K, Matsumoto T. Estimation of single stress fiber stiffness in cultured aortic smooth muscle cells under relaxed and contracted states: Its relation to dynamic rearrangement of stress fibers. J Biomech 2010;43:1443-9.

35 Calovini T, Haase $H$, Morano I. Steroid-hormone regulation of myosin subunit expression in smooth and cardiac muscle. J Cell Biochem 1995;59:69-78.

36 Haase $\mathrm{H}$, Morano I. Alternative splicing of smooth muscle myosin heavy chains and its functional consequences. J Cell Biochem 1996:60:521-8.

37 Siegman MJ, Butler TM, Mooers SU, et al. Hypertrophy of colonic smooth muscle: contractile proteins, shortening velocity, and regulation. Am J Physiol 1997;272: G1571-80. 